\title{
Presentation of severe haemophilia-A role for accident and emergency doctors?
}

\author{
H L Minhas, P L F Giangrande
}

\begin{abstract}
Background-The management of haemophilia has changed dramatically over the years and is constantly being improved. This study set out to discover if the diagnosis of haemophilia was being made early enough in those with no family history and looked at the different modes of presentation.

Method-A questionnaire was sent to all patients with haemophilia under the age of 16 who had no family history before diagnosis.

Results-There were 28 replies from 34 patients contacted ( $82 \%$ response rate). Three were excluded because of a known family history. The mean number of attendances to a doctor before a diagnosis was considered was 4.13 (median $=3$, interquartile range $=2.5$ ). The mean age of diagnosis was 29.52 months (median = 14 , interquartile range $=20$. Most presentations were to the accident and emergency department and to the general practitioner. The most common presenting feature was easy bruising.

Conclusion-There is a variable delay in diagnosis despite predictable presenting features.
\end{abstract}

(Emerg Med f 2001;18:246-249)

Keywords: haemophilia; diagnosis

Haemophilia is a congenital disorder of blood coagulation that arises as a result of a deficiency of clotting factor proteins, which are essential to the normal coagulation process. The classic form, haemophilia A, is attributable to deficiency of factor VIII while haemophilia B (also known as Christmas disease), which is clinically indistinguishable, is attributable to deficiency of factor IX. Both of these diseases have a classic X linked pattern of inheritance and thus affect males while females may be carriers of the condition. Haemophilia $\mathrm{A}$ is the more common variant of the disease and has an incidence of approximately 20 per 100000 males. $^{1}$

Both diseases have similar clinical features and clinical management. ${ }^{2}$ The most common manifestations of haemophilia are easy bruising and haemarthroses of the joints, ${ }^{3}$ although fatal haemorrhage can occur in an undiagnosed child especially after major trauma. The haemarthroses occur either spontaneously or with minimal trauma and a haemophilic child may bleed spontaneously two to three times a week. The most commonly involved joints are the knees, elbows and ankles although any joint may be involved. The sequelae of recurrent intra-articular haemorrhage are joint destruction and disability. ${ }^{4}$ The modern approach to treatment entails administration of coagulation factor concentrate intravenously on a prophylactic basis, two or three times a week to prevent spontaneous bleeds occurring. In the longer term, such treatment also prevents the development of joint damage and disability, which was a significant problem in the past. ${ }^{5}$ Modern coagulation factor concentrates carry no risk of transmission of hepatitis or HIV, which was a serious problem in the past, and now young haemophilic boys lead essentially normal lives and have a normal life expectancy.

Although haemophilia is a model of X linked disease inheritance, a significant number of cases (approximately 30\%) arise as a result of spontaneous mutations. ${ }^{6}$ In such cases of new mutations, patients will present without a family history of bleeding disorders. This may result in delayed diagnosis of this rare condition as well as inappropriate or unnecessary investigations. In such circumstances, it is not unusual for the possibility of physical abuse to be raised by health care professionals, causing emotional distress to both child and family.

On reviewing case records of some young haemophilic boys it was apparent that in some cases there had been a considerable delay in making the diagnosis, and this prompted us to investigate how the diagnosis had been established in a wider group of patients. The aim of this study was to examine the mode of presentation of these patients and thereby try to identify the causes of the delays in diagnosis. We believe that this is the first study of this kind as a search of the literature showed that no similar study has been published in recent years.

\section{Methods}

This study was performed using a retrospective questionnaire sent to patients attending the Oxford Haemophilia Centre, which serves a large geographical area. To study the population that is most likely to suffer a delay in diagnosis, it was decided to focus only on patients with no previous known family history of haemophilia. In addition, to reflect relatively recent practice, the inclusion criteria were further restricted to study only children under the age of 16 years.

The database at the Oxford Haemophilia Centre was used to provide the initial list of patients under the age of 16 . This yielded 125 patients in this age group. All patients had been originally coded as to whether or not there was a family history and the whole list of 125 patients was re-checked for any inaccuracies in 
the original coding. This gave a final total of 34 patients who were aged 16 or less with no known family history and who thereby fulfilled the inclusion criteria. Questionnaires were then sent to the parents of all 34 patients along with a covering letter requesting their participation. They were also asked to provide telephone numbers so that they could be contacted to clarify any points.

(1) Was there a history of haemophilia in your family before your son was born?

(2) Was a sample of blood taken from your son when he was born?

(3) How many times did you take your son to see a doctor (with bleeding bruising joint pain etc.) before the diagnosis was mentioned

(4) To whom did you take your child to be seen: General Practitioner

Accident and Emergency

Paediatrician

Orthopaedic

Other (please specify)

(5) Did you take your child to the doctor because of Easy bruising

Joint problems (please say which ones)

Bleeding

Other (please specify)

(6) Who made the diagnosis of haemophilia? General Practitioner

Accident and Emergency

Paediatrician

Orthopaedic

Haemophilia centre

Other (please specify)

(7) In hindsight do you think that diagnosis could have been made sooner?

If yes please comment

(8) How old was your child (in months) when the diagnosis was made?

(9) If you are happy to speak to me over the telephone regarding this study, please give your telephone number:

Dialing code

Telephone number

Thank you very much for your co-operation

Haemophilia in A\&E

Figure 1 Questionnaire used in the study.
QUESTIONNAIRE DESIGN

An example of the questionnaire with the full list of questions is given in figure 1 . The questionnaire was designed with a simple tick box format. The aim of the questions was to identify the areas that contributed to a delay in diagnosis and specific questions were posed relating to: the age of the patient at eventual diagnosis; to whom and how the patient had 
Table 1 Clinical data of the patients in the study

\begin{tabular}{|c|c|c|c|c|c|c|}
\hline Patient number & Haemophilia type & Factor level (\%) & $\begin{array}{l}\text { Initial } \\
\text { presentation * }\end{array}$ & $\begin{array}{l}\text { Number of } \\
\text { presentations to } \\
\text { diagnosis }\end{array}$ & $\begin{array}{l}\text { Contact with } \\
\text { healthcare stafft }\end{array}$ & $\begin{array}{l}\text { Diagnosis } \\
\text { suspected byt }\end{array}$ \\
\hline 1 & B & $2-5$ & $\mathrm{Br} / \mathrm{Bl}$ & 15 & $\mathrm{G} / \mathrm{O} / \mathrm{H}$ & $\mathrm{H}$ \\
\hline 2 & A & $<2$ & $\mathrm{Br}$ & 1 & G & G \\
\hline 3 & A & $<2$ & $\mathrm{Br}$ & 3 & $\mathrm{G} / \mathrm{A} / \mathrm{P}$ & $\mathrm{P}$ \\
\hline 4 & A & $<2$ & $\mathrm{Br} / \mathrm{Ha}$ & 5 & $\mathrm{G} / \mathrm{A} / \mathrm{P} / \mathrm{O}$ & $\mathrm{P}$ \\
\hline 5 & A & $<2$ & $\mathrm{Br}$ & 3 & $\mathrm{G} / \mathrm{P}$ & $\mathrm{P}$ \\
\hline 6 & A & $5-10$ & $\mathrm{Br}$ & 1 & $\mathrm{G} / \mathrm{P}$ & $\mathrm{P}$ \\
\hline 7 & A & $<2$ & $\mathrm{Ha}$ & 2 & $\mathrm{G} / \mathrm{O}$ & $\mathrm{O}$ \\
\hline 8 & A & $5-10$ & $\mathrm{Br}$ & 1 & G & G \\
\hline 9 & B & $>10$ & $\mathrm{Ha}$ & 2 & $\mathrm{G} / \mathrm{O}$ & $\mathrm{O}$ \\
\hline 10 & A & $<2$ & $\mathrm{Br} / \mathrm{Bl}$ & 2 & $\mathrm{~N}$ & $\mathrm{H}$ \\
\hline 11 & A & $<2$ & $\mathrm{Br} / \mathrm{Ha}$ & 2 & $\mathrm{G} / \mathrm{A}$ & A \\
\hline 12 & B & $<2$ & $\mathrm{Br}$ & 6 & G/A/P & $\mathrm{P}$ \\
\hline 13 & $\mathrm{~A}$ & $<2$ & $\mathrm{Bl}$ & 3 & $\mathrm{G} / \mathrm{A}$ & $\mathrm{A}$ \\
\hline 14 & A & $>10$ & $\mathrm{Br} / \mathrm{Bl}$ & 1 & $\mathrm{G} / \mathrm{N}$ & $\mathrm{N}$ \\
\hline 15 & A & $<2$ & $\mathrm{Ha}$ & 3 & $\mathrm{G} / \mathrm{O}$ & $\mathrm{O}$ \\
\hline 16 & A & $2-5$ & $\mathrm{Bl}$ & 19 & $\mathrm{G} / \mathrm{A} / \mathrm{N}$ & G \\
\hline 17 & A & $2-5$ & $\mathrm{Br}$ & 10 & $\mathrm{G} / \mathrm{A} / \mathrm{N}$ & $\mathrm{N}$ \\
\hline 18 & A & $<2$ & $\mathrm{Br} / \mathrm{Bl} / \mathrm{Ha}$ & 3 & $\mathrm{G} / \mathrm{N} / \mathrm{A}$ & A \\
\hline 19 & A & $2-5$ & $\mathrm{Br} / \mathrm{Bl}$ & 5 & $\mathrm{G} / \mathrm{H}$ & $\mathrm{H}$ \\
\hline 20 & A & $<2$ & $\mathrm{Br} / \mathrm{Ha}$ & 2 & $\mathrm{G} / \mathrm{A} / \mathrm{P}$ & $\mathrm{P}$ \\
\hline 21 & A & $<2$ & $\mathrm{Ha}$ & 1 & $\mathrm{~A} / \mathrm{H}$ & $\mathrm{H}$ \\
\hline 22 & B & $<2$ & $\mathrm{Br} / \mathrm{Ha}$ & 4 & $\mathrm{G} / \mathrm{P}$ & $\mathrm{N}$ \\
\hline 23 & A & $<2$ & $\mathrm{Br} / \mathrm{Ha}$ & 4 & $\mathrm{G} / \mathrm{A} / \mathrm{P}$ & $\mathrm{P}$ \\
\hline 24 & A & $<2$ & $\mathrm{Ha}$ & 3 & G & G \\
\hline 25 & A & $<2$ & $\mathrm{Br} / \mathrm{Ha}$ & 3 & $\mathrm{G} / \mathrm{A} / \mathrm{P}$ & G \\
\hline
\end{tabular}

${ }^{\star} \mathrm{Br}=$ bruising; $\mathrm{Bl}=$ bleeding; $\mathrm{Ha}=$ haemarthrosis. $\dagger \mathrm{G}=$ general practitioner, $\mathrm{A}=$ accident and emergency department; $\mathrm{P}=$ paediatric department; $\mathrm{O}=$ orthopaedic department; $\mathrm{H}=$ haematologist; $\mathrm{N}=$ other.

presented and the number of presentations before the correct diagnosis was made.

\section{Results}

The results of the responses to the questionnaire are given in table 1 and the analysis of these results is shown in table 2 and figures 2 and 3 . Of the 34 questionnaires sent out there were a total of $28(82 \%)$ replies. Three of 28 $(10 \%)$ of these had a positive family history of haemophilia, which had been previously missed and so were excluded from any further analysis. This left a final total of 25 patients who fulfilled the inclusion criteria and whose parents had responded to the questionnaire. Twenty one of the 25 patients $(84 \%)$ had haemophilia A. Seventeen of $25(68 \%)$ had factor VIII levels of $<2 \%$ while 6 of $25(24 \%)$ had levels of $2 \%-10 \%$. Two patients $(8 \%)$ had levels $>10 \%$

The number of attendances to a doctor before a diagnosis of haemophilia was considered, ranged from 1 to 19 (table 1). In only 5 of the $25(20 \%)$ patients was the diagnosis of haemophilia considered and investigated at the first presentation. The mean number of attendances before diagnosis for the group overall was 4.16 (mode $=3$, interquartile range 2-4.75) (table 2 and figure 2). When the more

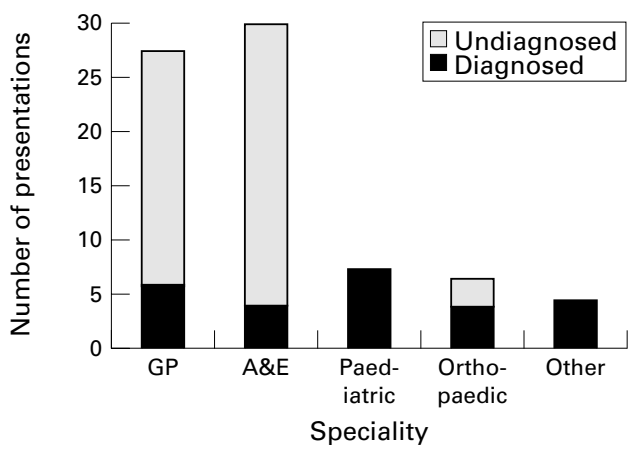

Figure 2 Number of presentations to each specialty. severe cases (that is, factor levels of $<2 \%$ ) were assessed, the mean number of presentations was 2.94 (mode $=3$, interquartile range $2-3$ ). The mean age at diagnosis for the group overall was 29.52 months but the mean age at diagnosis for the severe group was 18.17 months (table 2 and fig 3 ).

The most common clinical presentation was bruising, which was seen in 18 of $25(72 \%)$ patients (table 1). Seven of the 18 (39\%) patients with bruising $(28 \%$ of the overall group) had no other disease manifestations while 4 of $18(22 \%)$ and 7 of $18(39 \%)$ also had episodes of bleeding and haemarthroses respectively. One patient ( $5 \%$ ) had both bleeding and haemarthrosis together with the bruising. Only 5 of $25(20 \%)$ of the patients presented with haemarthroses alone and 2 of $25(8 \%)$ presented with bleeding alone. A total of 12 of 25 (48\%) had episodes of haemarthrosis, which occurred most commonly in the knee joints (table 2).

Contact with medical staff came through either the accident and emergency (A\&E) department or the general practitioner in all patients except one (24 of $25,96 \%)$. Ten of 24 $(41.6 \%)$ were eventually referred appropriately while 6 of $24(25 \%)$ were referred to a paediatrician and 5 of $24(21 \%)$ to an orthopaedic surgeon. A single case (1 of $24,4 \%$ ) was

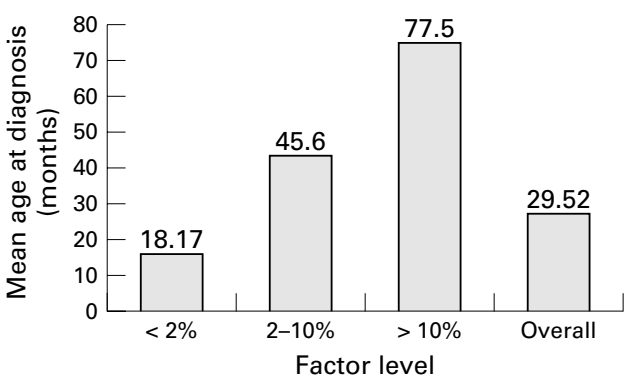

Figure 3 Association between factor levels and age at diagnosis. 
Table 2 Clinical presentation of children with haemophilia

\begin{tabular}{|c|c|c|c|c|c|c|c|}
\hline Specialty & $G P$ & $A \mathcal{E} E$ & Paediatric & Orthopaedic & Other & Haematologist & Total $^{*}$ \\
\hline Number of initial presentations & 27 & 29 & 7 & 6 & 4 & & 73 \\
\hline Diagnosis made & 5 & 3 & 7 & 3 & 3 & 4 & 25 \\
\hline \multirow[t]{2}{*}{ Presentation } & Bruise & Bleed & foint bleed & Other & & & \\
\hline & 18 & 7 & 12 & 0 & & & 37 \\
\hline \multirow[t]{2}{*}{ Which joint } & Hip & Knee & Ankle & Wrist & Elbow & & \\
\hline & 3 & 6 & 3 & 1 & 2 & & 15 \\
\hline Factor levels & $<2 \%$ & 2 to $10 \%$ & $>10 \%$ & & & & All \\
\hline Patients & 17 & 6 & 2 & & & & 25 \\
\hline Mean age at diagnosist & 18.17 & 45.6 & 77.5 & & & & 29.52 \\
\hline Total presentations & 50 & 51 & 3 & & & & 104 \\
\hline Mean presentations & 2.94 & 8.5 & 1.5 & & & & 4.16 \\
\hline Median number of presentations & 3 & 7.5 & 1.5 & & & & 3 \\
\hline IQR & $2-3$ & $2-13.75$ & $1.25-1.75$ & & & & $2-4.75$ \\
\hline
\end{tabular}

^Some totals may be greater than the total number of patients because of repeated episodes of presentation before diagnosis and more than one mode of presentation. †Age is given in months.

referred to both. In 2 of $24(8 \%)$ cases, the diagnosis was not made despite a life threatening perinatal bleed in hospital.

Three of the patients also had contact with non-hospital services (such as a dentist) and the single patient who did not have contact with either the general practitioner or the $\mathrm{A} \& \mathrm{E}$ department was referred directly to the haematologist by his dentist. In 6 of $25(24 \%)$ cases the question of child abuse was raised and in one of these cases the correct diagnosis was made during an investigation for possible physical abuse. Of all the respondents, 16 of 25 $(64 \%)$ parents felt that the diagnosis could have been made more quickly.

\section{Discussion}

Haemophilia is a rare congenital disorder of coagulation, characterised by repeated and spontaneous haemarthroses and also internal bleeding. Few clinicians will have direct clinical experience of this condition, and it is therefore not entirely surprising that there is often a delay in the diagnosis of new cases. Nevertheless, early recognition is important to establish correct treatment and this may also avoid unnecessary investigations for physical abuse. Although this is a small study, some important general observations may be made and lessons can be learnt. This study showed that the primary diagnosis was delayed in $80 \%$ of cases. The primary cause for delayed diagnosis was the failure among physicians to recognise the disease when presented with the clinical features. Forty eight per cent of presentations were to A\&E departments. Most patients presented to a physician four times, one 19 times! Confusion may arise when haemarthosis is not the presenting problem: this study and others have shown that marked bruising (rather than haemarthrosis) may be the first presenting feature. ${ }^{3}$ This study shows that there probably is a lack of knowledge of bleeding disorders among general physicians. It is possible that our clinical diagnosis of this condition has improved in the year 2001 as compared with the late 1980s and the 1990s; however there is no published evidence to suggest this is the case.
The important message of this study is that the diagnosis of haemophilia should at least be entertained in young boys who present with a haemarthrosis, recurrent limping or marked purpuric bruising. The joints most usually affected with spontaneous haemarthrosis are the ankles, knees and elbows. Most importantly, the absence of a documented family history of this condition does not exclude the possibility of haemophilia as approximately one third of all cases arise as new mutations. Once the diagnosis has been considered, a simple clotting screen should help to resolve any doubt. The prothrombin time is normal in haemophilia, while the activated partial thromboplastin time will be markedly prolonged. This can then be followed up in the haematology laboratory with specific assays of coagulation factors VIII and IX.

Early diagnosis will minimise the risk of complications. This article contains guidance on the clinical features of haemophilia and the haematological investigations that will help to identify the condition.

Contributors

The study was conceived by Dr Honeyia Minhas (HM). The methods and questionnaire for the study were designed by $\mathrm{HM}$ and Dr Paul Giangrande (PG). The data were collected by HM and analysed by HM with statistical advice from Dr Ed Juszczak. The manuscript was written by HM and PG. Dr David Keeling helped to devise the questionnaire. Miss Alison at the Oxford Haemophilia Centre helped to retrieve and check data.

Funding: none.

Conflicts of interest: none.

1 Levin PH. Clinical manifestations and therapy of hemophilias A and B. In: Colman RW Hirsh J, Marder VJ, et al, eds. Hemostasis and thrombosis:basic principles and clinical eds. Hemostasis and thrombosis:basic principles and clinical
practice. 2nd ed. Philadelphia: J B Lippincott, 1987:97practice.

2 Bloom AL. Inherited disorders of blood coagulation. In: Bloom AL, Thomas DP, eds. Haemostasis and thrombosis. 2nd ed. Edinburgh: Churchill Livingstone, 1987:393-436.

3 Morgan LM, Kissoon N, de Vebber BL. Experience with the hemophiliac child in a pediatric emergency department. $\mathcal{F}$ Emerg Med 1993;11:519-24.

4 Rodriguez-Merchan EC. Pathogenesis, early diagnosis, and prophylaxis for chronic hemophilic synovitis. Clin Orthop 1997;343:6-11.

5 Lusher JM, Warrier I. Hemophilia A. Hematol Oncol Clin North Am 1992;6:1021-33.

6 Hoyer LW. Hemophilia A. N Engl f Med 1994;330:38-47.

7 Ljung R, Petrini P, Nilsson. Diagnostic symptoms of severe Ljung R, Petrini P, Nilsson. Diagnostic symptoms of severe
and moderate haemophilia A and B. Acta Paediatr Scand 1990;79:196-200. 